\title{
TLR receptors in laryngeal carcinoma - Immunophenotypic, molecular and functional studies
}

\author{
Jan Sikora, Magdalena Frydrychowicz, Mariusz Kaczmarek, Bartosz Brzezicha, \\ Iwona Mozer-Lisewska, Mirosław Szczepański, Jan Żeromski
}

\author{
Chair and Department of Clinical Immunology, Infectious Diseases, University of Medical Sciences, \\ Poznan, Poland
}

\begin{abstract}
Toll-like receptors (TLRs) have been shown to play crucial role in the recognition of unicellular pathogens. We have shown the expression of three TLRs on tumor cells of human laryngeal carcinoma by means of immunohistochemistry. In the current study we searched presence of TLR1-10 on protein and molecular level in larynx carcinoma cell lines and the impact of respective TLR ligands on TLR expression. Larynx carcinoma cell lines have been used. Cell were subjected to immunocytochemistry. RNA isolated from the cells was tested by RT-PCR. Cells were cultured in the presence of respective TLR ligands. Cells than were harvested and subjected to flow cytometry, using anti TLR1-10 Moabs. The cells were evaluated of membrane and cytoplasmic cell staining. TLR reactivity varied in individual cell lines. RT-PCR allowed to show mRNA for all TLRs tested. After short-term cell culture each cell line exhibited distinct pattern of expression of TLRs following interaction with respective ligand. Cytoplasmic TLR staining had usually higher MFI value than membrane one, but after culture with ligand it became reversed. TLRs 7 and 9 showed highest expression in the majority of tumor cells tested. In conclusion, larynx carcinoma cell lines exhibit rather universal expression of TLRs, both on protein and molecular level. Culture of TLR expressing tumor cells with ligands points out for potential reactivity of tumor cells with TLR agonists, what may have therapeutic implications.
\end{abstract}

Key words: Toll-like receptors; laryngeal carcinoma; cell lines; cell culture; flow cytometry; RT-PCR

\section{Introduction}

Toll-like receptors (TLRs) a portion of the family of Pattern Recognition Receptors (PRR) have gained great interest in scientific community. This group of highly conserved receptors, initially restricted to cells of the immune system, was shown to activate innate and adaptive immune responses. Later TLRs were demonstrated on cells of various epithelia. Their ability to act as sensors of various pathogens, to discriminate between self and non-self provided new tools and weapons in the struggle for good health and survival of human beings. TLRs exist in several families differing in the ability of recognition of particular ligand such as sugars, complex lipids, nucleic acids and other, collectively called Pathogen Recognition Molecular Patterns (PAMPs). All of them are natural ligands of TLRs able to activate

Corresponding: J. Żeromski, Chair and Dept. of Clinical Immunology, Infectious Diseases, University of Medical Sciences, Poznan, Poland; tel. $(+48)$ 8547172,

fax.: (+48) 8547173, e-mail: jzeromski@ump.edu.pl intrinsic cell machinery following TLR-ligand binding. This in turn results in activation of transcription factors such as NF- $\mathrm{kB}$ and their penetration to cell nucleus. This leads to transcription of several genes encoding, among others proinflammatory cytokines [1,2]. During last $10-20$ years it became obvious that TLRs play pivotal role in various pathological conditions, especially local and systemic infections, because they trigger both innate and adaptive immunity of the affected host [3]. Apart from natural ligands derived mainly from various pathogens there is an evidence that various substances from our body may act as TLR ligands, often being result of metabolism or pathologic process such as uric acid, heat shock proteins, apoptotic fragments and others. They are known as Danger Associated Molecular Patterns (DAMPs) [4]. The third type of TLR ligands are synthetic agonists of TLRs, produced more and more often by pharmaceutical companies.

Abbreviations: TLRs - Toll-like receptors; PAMPs - pathogenassociated molecular patterns. 
Table 1. Larynx carcinoma cell lines used.

\begin{tabular}{|l|c|c|c|}
\hline \multicolumn{1}{|c|}{ Symbol } & Sex & TNM stage & Doubling time, $\mathrm{h}$ \\
\hline PCI19 & $\mathrm{M}$ & T3N0M0 & \\
\hline PCI37A & $\mathrm{M}$ & T3N2M0 & 80 \\
\hline PCI37B & $\mathrm{M}$ & T3N2M0 & 91 \\
\hline PCI4B & $\mathrm{M}$ & T3N0M0 & 58 \\
\hline Hep2 & $\mathrm{M}$ & - & \\
\hline UT35 & $\mathrm{M}$ & T2N0M0 & \\
\hline
\end{tabular}

Source: [9]

Apart from normal epithelia, TLRs have been shown to be expressed on cells of several cancers, including skin [5], breast [6], lung [7], colon [8], liver [9], ovary [10] and other tumors [11]. Cells of particular cancers express various TLRs and their wealth suggests that they may fulfill some function related to tumor growth and progression. In fact, it was demonstrated by several investigators, that TLRs may act in favor of tumor, providing positive stimuli for its progression. On the other hand, appropriate TLR ligands may suppress tumor growth, as it was noticed in some tumors. For example imiquimod, man-made ligand for TLR7, was shown to inhibit growth of skin carcinoma when applied as an ointment $[12,13]$. The positive effect of imiquimod was found to be immunologically mediated, because it was due up-regulation of effector function of T cells [14].

We have shown that the cells of laryngeal carcinoma express at least three TLRs, namely TLR2, TLR3 and TLR4 [15]. It was detected by means of immunohistochemistry on frozen tissue sections of surgical specimens of this tumor. In order to get more information about the expression and function of TLRs in this cancer we decided to search for other TLRs on established cell lines of this tumor and to culture them in the presence of appropriate TLR ligands. It will be shown that there is a wide distribution of TLRs in the cancer in question and that their expression seems to be functional, as evidenced by the movement of TLR protein from cell interior to cell surface, following contact with respective ligand.

\section{Materials and methods}

Cell line and culture conditions. Cell lines used included four ones obtained from Pittsburgh Cancer Institute (PCI), USA, courtesy of prof. Theresa Whiteside, one (HeP2) from ATCC collection (ATCCCCL23) and one (UT-35) obtained owing to courtesy of Prof. K. Szyfter (Institute of Human Genetics, Polish Academy of Sciences, Poznan, Poland). Their basic characteristics are shown in Table 1. All cell lines were cultured in RPMI 1640 medium supplemented with $10 \%$ fetal calf serum (FCS), 2mM L-glutamine and antibiotics, penicillin + streptomycin in final concentration of each $100 \mu \mathrm{g} / \mathrm{ml}$ in standard culture conditions $37^{\circ} \mathrm{C}, 5 \% \mathrm{CO}_{2}$ and $95 \%$ humidity.
Immunocytochemistry. Cells were released from the bottom culture flask by treatment with $1 \%$ trypsin. In order to restore cell surface molecules digested by the enzyme, cells were suspended for $24 \mathrm{hrs}$ in 10\% FCS. Cell sediments (cytospins) were prepared thereafter by means of cytocentrifuge (Shandon) at $1000 \mathrm{rpm} / \mathrm{min}$ for $4 \mathrm{~min}$. Cytospins were dried, fixed in chilled acetone for 10 min, dried again and subjected overnight at $40^{\circ} \mathrm{C}$ in humid chamber to the reaction with respective polyclonal (goat) antibodies anti-TLR2 up to TLR10. Their basic characteristics and source are shown in Table 2. The cells were then extensively washed in TBS (physiological saline buffered with TRIS buffer $\mathrm{pH} 7,6$ ), incubated with anti-goat secondary antibody and thereafter subjected to $\mathrm{ABC}$ (Avidin Biotin peroxidase anti peroxidase Complex) reaction, using commercial $\mathrm{ABC}$ kit (Santa Cruz Biotechnology). Reaction product was visualized by means of DAB (diaminobenzidine). Cells were washed later as above and counterstained with Mayer's hematoxylin, washed in tap water and embedded in glycerogel. Control reactions included replacement of primary antibody by TBS and preincubation of primary antibody with respective blocking peptide (Santa Cruz) used previously for the production of given TLR antibody. In addition, red blood cells and cultured human fibroblasts were tested using TLR antibodies. All control reactions gave uniformly negative results.

The cytospins following immunohistochemical reaction were assessed at high power light microscope by semiquantitative way by two independent observers. Four compartments of reaction positivity were delineated:

$+++75-100 \%$ positive cells

$++25-75 \%$ positive cells

$+>25 \%$ positive cells

- lack positive cells

Apart from the percent of positive cells the attention was also paid to localization of the reaction product. The latter could be discerned as cell surface bound and cytoplasmic one.

Cancer cell line co-culture with TLR ligands. Six cancer cell lines (Table 1 ) in a quantity $5 \times 10^{5}$ cells per well, were cultured for $24 \mathrm{hrs}$ in the presence of TLR ligands. The list of ligands used is shown in Table 3. Quantities of particular ligand added to the culture was in accordance with recommendations of the manufacturer (InVivoGen). Control cells were cultured in a parallel without added ligand.

After termination of culture cells were resuspended in PBS and subjected to respective anti-TLR fluorochrome labeled monoclonal antibody (Moab) reaction, with the specificity corresponding to used ligand. TLR1, 2, 3 and 4 Moabs were purchased in Santa Cruz Biotechnology, while TLR5, 6, 7, 8, 9 and 10 ones originated from IMGENEX. The direct immunofluorescence was carried out with the exception of anti TLR7, in which following unlabelled primary antibody anti mouse IgG1-FITC was applied. In each case control reaction was carried out using labelled mouse IgG1FITC/IgG2aPE in order to exclude non-specific fluorescence of used antibodies (isotypic control). Cells were incubated with appropriate reagent for $15 \mathrm{~min}$ in the dark. After extensive washing $10^{4}$ cells were subjected to acquisition in flow cytometric analyser Canto (BD) and analysed by Fax Diva software.

Total RNA isolation and RT-PCR. Total RNA was isolated using TRIzol Plus RNA Purification Kit (Invitrogen), starting with 6-9 $\times$ $10^{6}$ cells. Cell lines used for isolation were: PCI 4B, PCI 19, PCI 37A, PCI 37B, SSC UT 35 and Hep 2. Total RNA was isolated according to the kit manufacturer's recommendations. After isolation the amount of RNA was measured using NanoDrop ND 1000 UV-Vis Spectrophotometer (NanoDrop Technologies) and frozen.

RT-PCR reaction was performed using OneStep RT-PCR Kit (Qiagen) with $1 \mu \mathrm{g}$ of total RNA for each reaction tube. The protocol of reaction was supplied in manufacturer's handbook. Primers for 
Table 2. Anti-TLR primary antibodies used.

\begin{tabular}{|l|c|c|c|c|}
\hline \multicolumn{1}{|c|}{ Specificity } & Symbol & Species and Ig & Catalogue No. & Source \\
\hline Anti-human TLR1 & N-20 & Goat IgG & Sc-8687 & Santa-Cruz Biotech. \\
\hline Anti-human TLR2 & N-17 & Goat IgG & Sc-8689 & As above \\
\hline Anti-human TLR3 & N-14 & Goat IgG & Sc-8691 & As above \\
\hline Anti-human TLR4 & C-18 & Goat IgG & Sc-8694 & As above \\
\hline Anti-human TLR5 & N-15 & Goat IgG & Sc-8695 & As above \\
\hline Anti-human TLR6 & N-18 & Goat IgG & Sc-5657 & As above \\
\hline Anti-human TLR7 & I-20 & Goat IgG & Sc-13208 & As above \\
\hline Anti-human TIR8 & D-14 & Goat IgG & Sc-17585 & As above \\
\hline Anti-human TLR9 & N-15 & Goat IgG & Sc-13215 & As above \\
\hline Anti-human TLR10 & V-20 & Goat IgG & Sc-23577 & As above \\
\hline
\end{tabular}

Table 3. TLR ligands used.

\begin{tabular}{|l|c|c|c|c|}
\hline \multicolumn{1}{|c|}{ I.igand } & Specificity & $\begin{array}{c}\text { Concentration } \\
\text { used }\end{array}$ & Source & $\begin{array}{c}\text { Catalog } \\
\text { code }\end{array}$ \\
\hline LTA-SA (lipoteichoic acid from S. aureus & TLR-2 & $200 \mathrm{ng} / \mathrm{ml}$ & InVivoGen & tirl-sita \\
\hline LPS from P.gingivalis & TLR-2 & $20 \mathrm{ng} / \mathrm{ml}$ & As above & tirl-pglps \\
\hline Poly (I:C)-synthetic analogue of dsDNA & TLR-3 & $200 \mathrm{ng} / \mathrm{ml}$ & As above & tirl-picv \\
\hline LPS from E. coli & TLR-4 & $20 \mathrm{ng} / \mathrm{ml}$ & As above & tirl-cblps \\
\hline Flagellin from B.subtilis & TLR-5 & $20 \mathrm{ng} / \mathrm{ml}$ & As above & tirl-bsfla \\
\hline Imiquimod (synthetic) & TLR-7 & $3 \mu \mathrm{g} / \mathrm{ml}$ & As above & tirl-imq \\
\hline $\begin{array}{l}\text { ssPolyU/LyoVec (single stranded poly(U) oligonucleotide complexed } \\
\text { with LyoVecTM) }\end{array}$ & TLR-8 & $5 \mu \mathrm{g} / \mathrm{ml}$ & As above & tirl-lpu \\
\hline ODN - CpG oligonucleotide type B & TLR-9 & $10 \mu \mathrm{g} / \mathrm{ml}$ & As above & tirl-modna \\
\hline
\end{tabular}

GAPDH gene were used as an internal control. 35 cycles with annealing temperature of $54^{\circ} \mathrm{C}\left(61^{\circ} \mathrm{C}\right.$ for TLR7) were performed on Mastercycler epgradient (Eppendorf) thermocycler. Reaction products were resolved by $1.5 \%$ agarose electrophoresis, stained with ethidium bromide and visualised on UV transilluminator. GeneRuler $100 \mathrm{bp}$ Plus DNA Ladder (Fermentas) was used as a mass marker.

Since RT-PCR reaction for TLR7 was negative on RNA extracted from all used cell lines, an gradient RT-PCR reaction was performed. According to the results of gradient RT-PCR reaction, in repeated experiment a higher temperature of annealing $\left(61^{\circ} \mathrm{C}\right)$ was used in case of TLR7. The sequence of primers used and expected product sizes are shown in Table 4 .

\section{Results}

\section{Immunocytochemistry (ICC) on cell sediments}

All cell lines expressed some TLRs when tested versus TLR2-10 antibodies. Individual cell lines differed however in the reactivity with particular anti-TLR reagents. Most of cells expressed cytoplasmic staining, but some have shown membrane-bound reaction, when tested with given antibody. When TLR antibodies were mixed and incubated with respective blocking peptide prior the reaction with cells, the staining came out uniformly negative. Detailed data of cells reactivi- ty with anti-TLRs are depicted in the Table 5. Examples of ICC staining are depicted in Fig. 1.

\section{RT-PCR studies}

Results of RT-PCR studies are shown in the Fig 2

RT-PCR results showed that mRNAs for almost all TLRs examined in this study were expressed in cell lines studied. The expression level differed depending on the TLR being examined and cell line used for RNA isolation. Only one reaction product was not observed on agarose gel (TLR3 in PCI 37A). Bands of few RT-PCR products were much weaker comparing to others. They included TLR2 in SSC-UT-35, TLR7 in PCI 4B, TLR9 in PCI 4B, PCI 19, Hep-2 TLR10 in Hep-2. On the other hand, mRNAs for TLR1, TLR4, TLR6 had uniformly strong expression.

RT-PCR for TLR7 performed in higher temperature $\left(61^{\circ} \mathrm{C}\right)$ of annealing (see: Materials and methods) resulted in visible reaction products. The same reaction for TLR7 performed in annealing temperature of other TLRs $\left(54^{\circ} \mathrm{C}\right)$ gave no visible products (see Fig. 2). We decided to perform gradient RT-PCR reaction, thereafter the annealing temperature for TLR7 RT-PCR was set at $61^{\circ} \mathrm{C}$ for further experiments. 


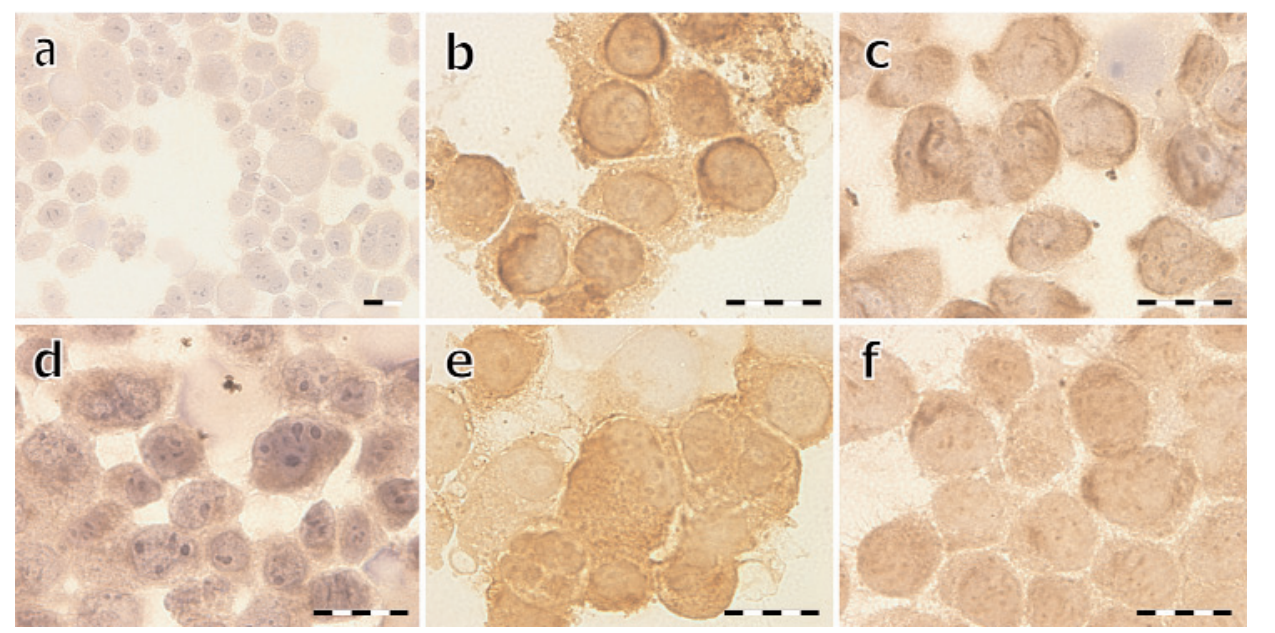

Fig. 1. Examples of immunocytochemistry reactions of larynx carcinoma cells with anti-TLR Abs. a. Hep2 cells. Normal goat serum instead of TLR antibody, followed by ABC staining kit. Control reaction (original magnification $\mathrm{x} 40$ ). b. PCI 37A cells. Anti-TLR3 Ab. Surface staining of cells (original magnification $\times 100$ ). c. PCI 37B cells. Anti-TLR4 Ab and as above. Partial surface staining of cells (original magnification $\times 100$ ). d. PCI37B cells. Anti-TLR9 Ab, and as above. Cytoplasmic staining of cells (original magnification $\times 100$ ). e. Hep2 cells. Anti-TLR7 Ab and as above. Cytoplasmic staining of cells (original magnification $\times 100$ ). f. PCI37B cells. Anti-TLR10 Ab and as above. Cytoplasmic staining of cells (original magnification $\times 100$ ). $\mathrm{Bar}-20 \mu \mathrm{m}$.
Table 4. Sequences of primers used in RT-PCR reaction and expected product sizes.

\begin{tabular}{|c|c|c|}
\hline Gene & Sequence & $\begin{array}{l}\text { Expected } \\
\text { product } \\
\text { size (bp) }\end{array}$ \\
\hline TLRl & $\begin{array}{l}\text { CTTATAAGTGTGACTACCCGG } \\
\text { CCACAATGCTCTTGCCAGG }\end{array}$ & 384 \\
\hline TLR2 & $\begin{array}{l}\text { GTTAACAATCCGGAGGCTGC } \\
\text { TTGGGAATGCAGCCTGTTAC }\end{array}$ & 438 \\
\hline TLR3 & $\begin{array}{l}\text { CCCTTGCCTC } \triangle \text { CTCCCC } \\
\text { CCTCTCCATTCCTGGCCT }\end{array}$ & 346 \\
\hline TLR4 & $\begin{array}{l}\text { CTGCAATGGATCAAGGACCA } \\
\text { TCCCACTCCAGGTAAGTGTT }\end{array}$ & 623 \\
\hline TLR5 & $\begin{array}{l}\text { TGGGGG } \wedge \wedge \text { CTTT } \wedge \text { C } \wedge \text { GTTCG } \\
\text { CTGGGATTCTCTGAAGGGG }\end{array}$ & 379 \\
\hline TLR6 & $\begin{array}{l}\text { GGGTTGAGAGTATAGTGGTG } \\
\text { GTAGATGCAGAGGGAGGTC }\end{array}$ & 548 \\
\hline TLR7 & $\begin{array}{l}\text { СТСССТGG } \triangle \text { TCTGT } \wedge C \wedge C C T G T G \wedge G \\
\text { СТCССACAGAGCCTTTTCCGGAGCT }\end{array}$ & 552 \\
\hline TLR8 & $\begin{array}{l}\text { AAACTTGAGCCACAACAACATIT } \\
\text { ATCTCCAATGTCACAGGTGC }\end{array}$ & 580 \\
\hline TLR9 & $\begin{array}{l}\text { AACTGGCTGTTCCTGAAGTC } \\
\text { TGCCGTCCATGAATAGGAAG }\end{array}$ & 394 \\
\hline TLR 10 & $\begin{array}{l}\text { AAAACTCTAAATGCGGGAAGAAA } \\
\text { GAAATAAATGCGTGGAATCGGA }\end{array}$ & 374 \\
\hline GAPDH & $\begin{array}{l}\text { TGAAGGTCGGAGTCAACGGATTTGGT } \\
\text { CATGTGGGCCATGAGGTCCACCAC }\end{array}$ & 983 \\
\hline
\end{tabular}

\section{Cell culture studies}

Cells of each cell line tested were cultured for $24 \mathrm{hrs}$ with or without respective TLR1-10 ligands. Following culture cells were washed and subjected to the reaction with TLR Moabs and evaluated by flow cytometry for MFI (Mean Fluorescence Intensity) expression.
In general, cytoplasmic expression dominated over that without prior incubation with ligand. Culture of cells with ligand resulted usually in the decrease of cytoplasmic MFI. In contrast, MFI surface expression of some TLRs was higher after ligand exposure. TLR1, TLR6 and TLR10 were cultured in medium only, because their ligands were not available. The reactivity of all cell lines with and without contact with ligands is shown in Fig. 3 (A-F). It is visible that MFI of individual TLRs varied on particular cell lines but that of some TLRs, namely TLR 7, 9 and partly TLR5 appeared apparently high on most cell lines. Curiously enough, culture with ligand resulted in the fall of some cytoplasmic TLR expression on the expense of surface one. It has been depicted in Fig. 4, where as a example of it, TLR7 on HeP-2 cells have shown such bizarre shift of expression.

\section{Discussion}

Tumor established cell lines do not reflect precisely properties and traits of neoplastic cells growing in vivo. They are not under influence of several factors derived from tumor bearing host, such as tumor infiltrating inflammatory cells, cytokines, cell adhesion molecules etc. On the other hand, cell lines provide several advantages in study of cancer biology such as sample homogeneity, the ease of culture and its various modifications and the least but not the last, avoidance of animal studies [16].

Laryngeal carcinoma, major representative of head and neck cancer group, is the fourth the most common malignancy of middle-aged and old men in Poland responsible for high mortality. In spite of the fact that more than $90 \%$ of these tumors are highly differentiated squamous cell carcinomas, mortality rates for this 
Table 5. TLRs expression on larynx carcinoma cell lines. Immunocytochemical studies.

\begin{tabular}{|l|c|c|c|c|c|c|c|c|c|c|}
\hline \multicolumn{1}{|c|}{ Cell linc } & TLR2 & TLR3 & TLR4 & TLR5 & TLR6 & TLR7 & TLR8 & TLR9 & TLR10 & Control \\
\hline PCI-19 & - & - & ++ & + & - & - & - & ++ & ++ & - \\
\hline PCI-37A & +++ & +++ & ++ & + & + & + & + & + & - & - \\
\hline PCI-37B & + & + & ++ & + & - & - & - & ++ & ++ & - \\
\hline PCI-4B & - & - & + & - & - & - & - & + & - & - \\
\hline Hep-2 & ++ & ++ & ++ & + & - & ++ & ND & ++ & ++ & - \\
\hline UT-35 & - & - & - & - & +1 & - & - & 11 & - & - \\
\hline
\end{tabular}

ND - not done
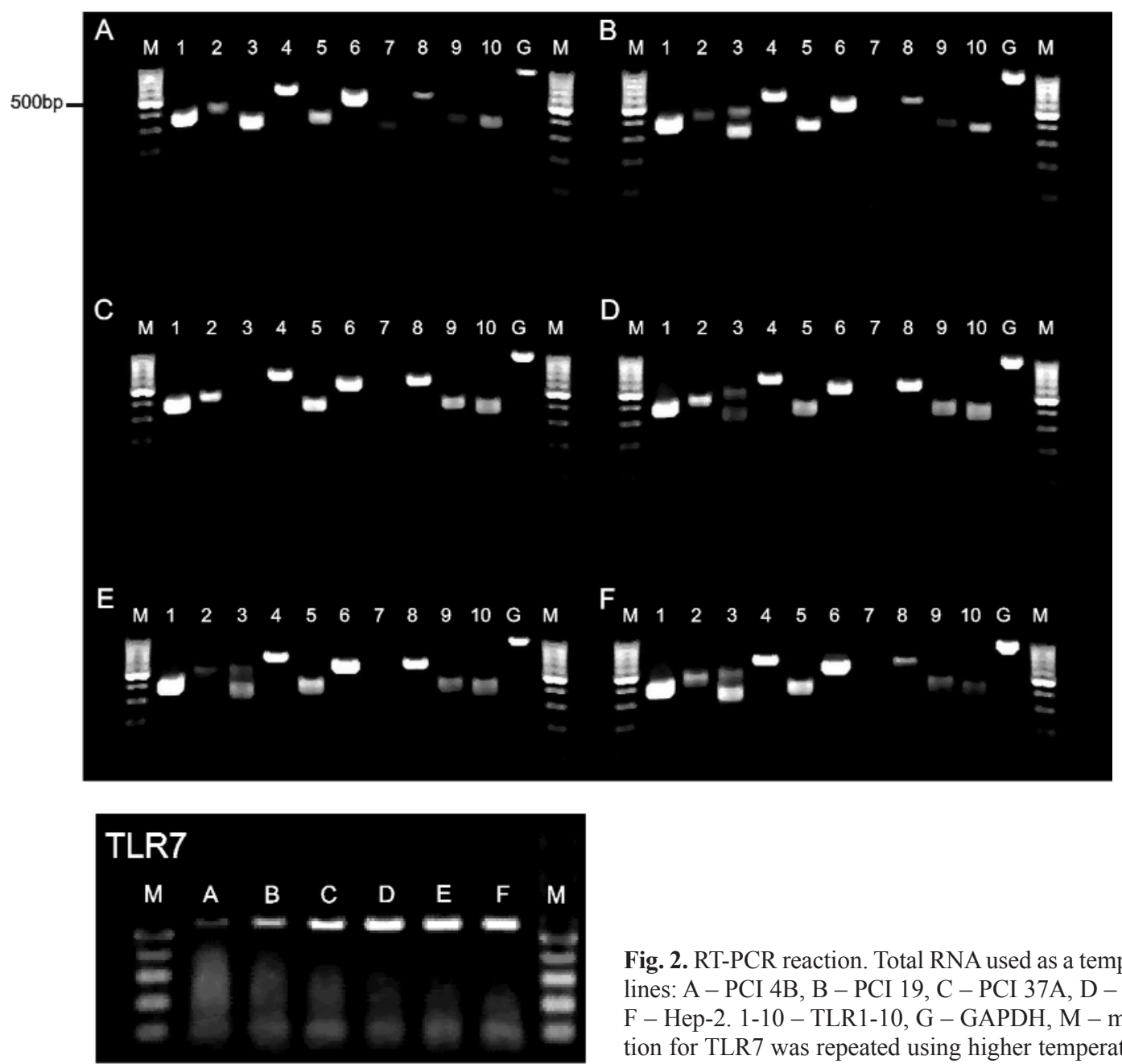

Fig. 2. RT-PCR reaction. Total RNA used as a template was isolated from cell lines: A - PCI 4B, B - PCI 19, C - PCI 37A, D - PCI 37B, E - SSC-UT-35, F - Hep-2. 1-10 - TLR1-10, G - GAPDH, M - mass marker. RT-PCR reaction for TLR7 was repeated using higher temperature of annealing $\left(61^{\circ} \mathrm{C}\right)$.

disease have not improved significantly in the past 50 years. It is typical environmental cancer in which major etiological role is played by smoking and associated alcoholic beverages. Its immunological and genetic features have been studied extensively. Several molecular aberrations in this tumor were described as well as the existence of specific cell-mediated immunity $[17,18]$ The latter however, has been shown to have no major impact on tumor growth and progression. This explains the current trend in tumor immunology to shift to evolutionally older, evolutionarily conserved branch of immunology, namely innate immunity. The latter ensures protection to myriads of various invertebrate creatures, is active from the very beginning of life and possess robust means and mechanisms for anti-microbial defense. Moreover, from unknown reasons, invertebrates are practically free from neoplasia. Fortunately, most of mechanisms of innate immunity have been preserved in vertebrates including man. Toll-like receptors are good example of 

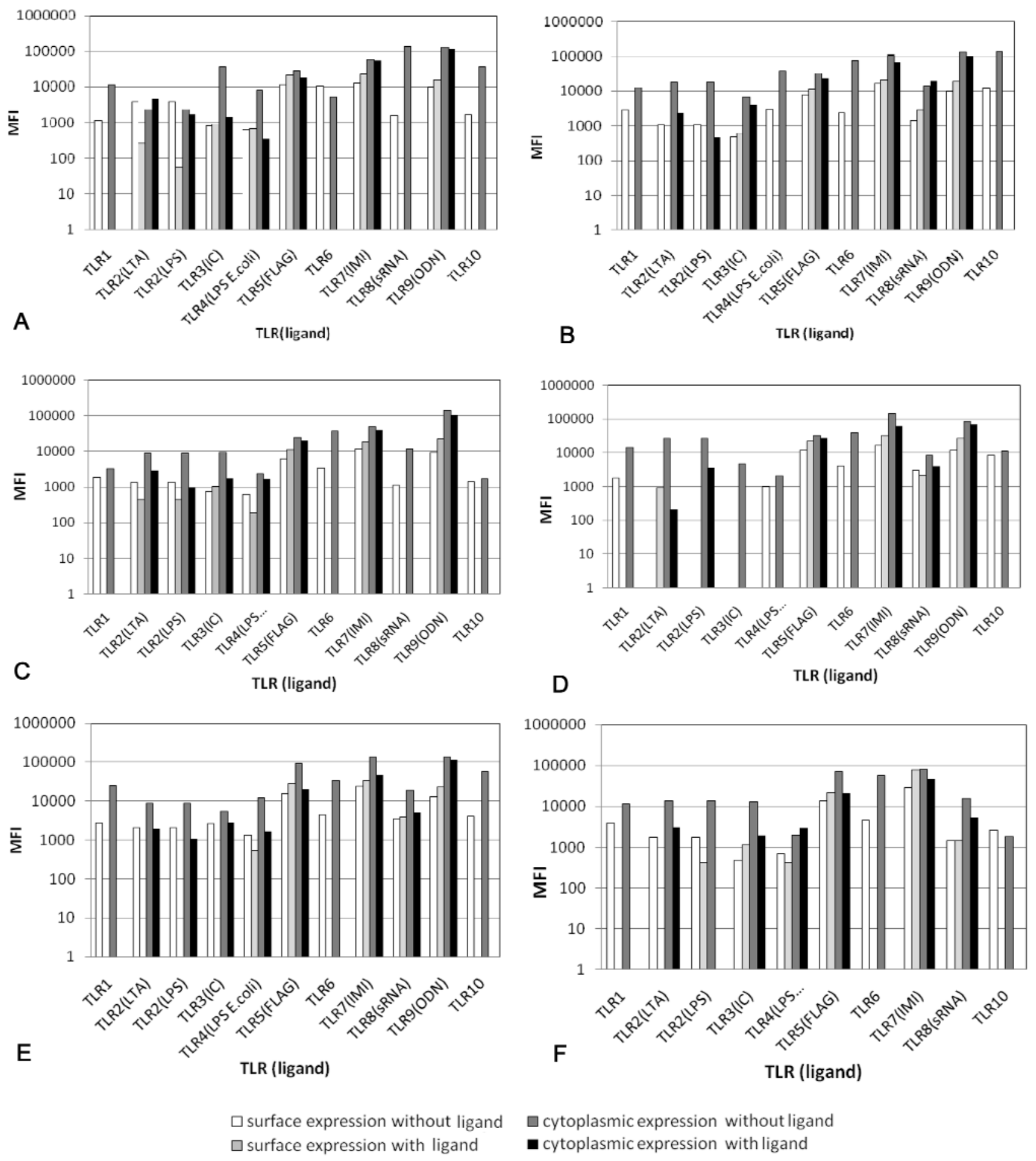

Fig. 3. Short-term culture of cancer cell lines with TLR ligands. Surface and cytoplasmic MFI expression of given TLR before and after culture with respective ligand A - Hep-2 line, B - UT35, C - PCI19, D - PCI37A, E - PCI37B, F - PCI4B.

such mechanism. They were initially detected in a Drosophila fly and were found to be involved in its dorso-ventral embryonic development and anti-fungal immunity [19]. TLRs are now well established factors participating in recognition of several bacterial, viral and fungal pathogens, both in animals and man. Their role in tumors is far from clear, but the interest is growing due to several reports in the literature claiming various, both positive and negative impact on tumor growth.

We have studied initially the expression of TLRs on six established cell lines of larynx cancer by means of 


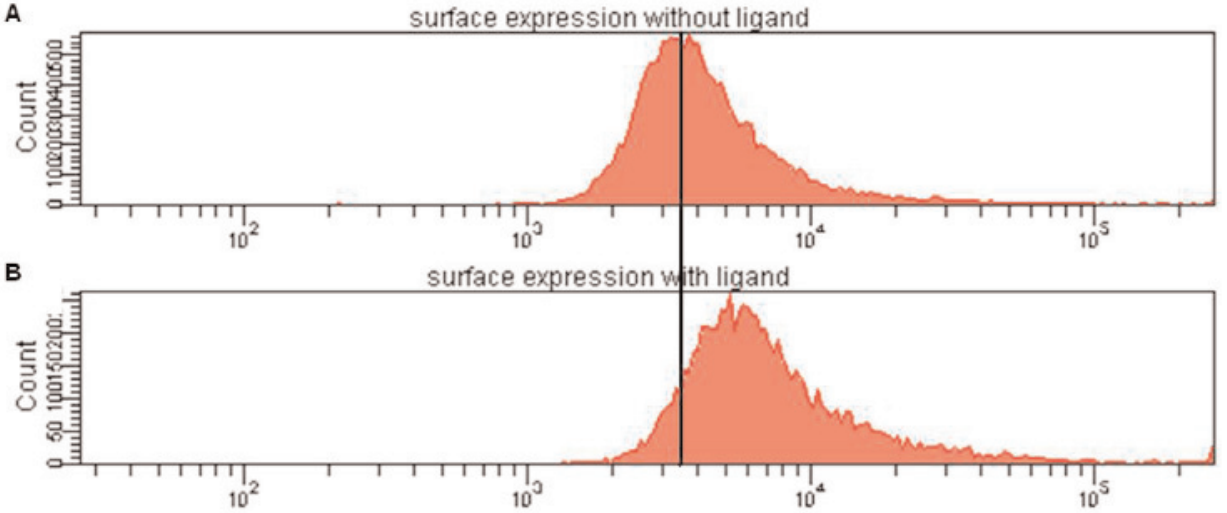

C

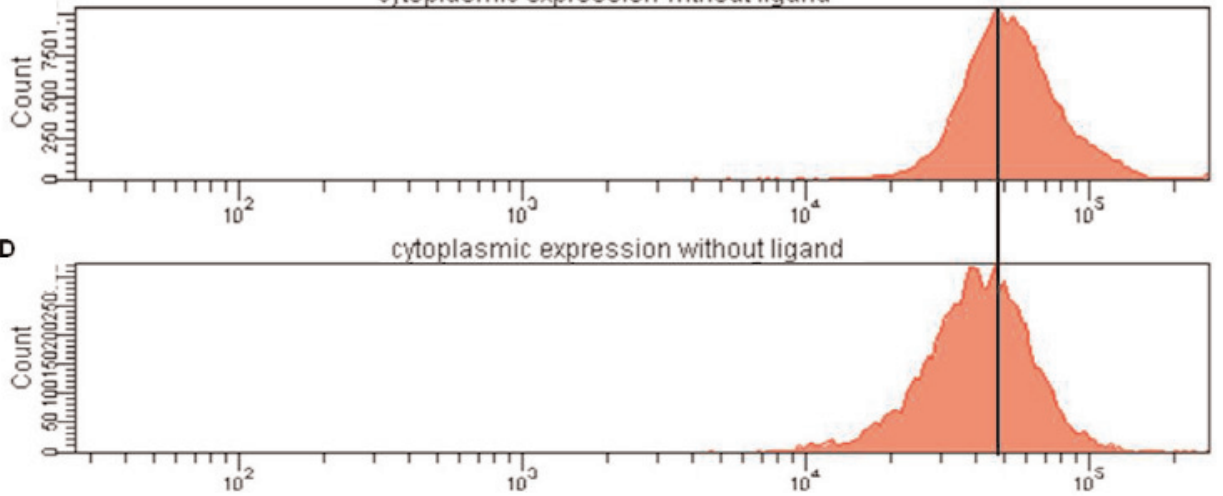

Fig. 4. (A) Surface expression of TLR7 on HeP-2 cells cultured without ligand. (B) As above but in the presence of ligand. Visible an increase of surface TLR7 expression following culture with ligand. (C) Cytoplasmic expression of TLR7 on HeP-2 cells cultured without ligand. (D) As above but in the presence of ligand. Visible fall of TLR7 expression, presumably due to its expulsion on cell surface. immunocytochemistry. Unexpectedly, we found almost universal expression of TLRs from 2 to 10 on some but not all cell lines. Cytoplasmic TLR expression dominated over surface bound one and the percent of positive cells ranged from 10 to 100 . PCI37A, PCI37B and Hep-2 cell lines demonstrated relatively highest expression. The cause of it is unknown, but at least two from the above mentioned cancers have been metastatic (see Table 1). It might suggest that high expression of TLRs may promote tumor growth. It is in line with reports of other investigators which have shown enhancing effect of TLR4 and TLR 9 on tumor growth respectively $[20,21]$. Some of us have demonstrated recently tumor growth promoting effect of TLR4 in squamous cell head and neck carcinomas [22]. It is of interest that in molecular studies of the current work mRNA of TLRs from 1 to 10 could be detected by rt PCR reaction in all cell lines tested. It indicates that cancer cells possess molecular potential ready to produce TLR protein molecules if needed for tumor advantage. It is plausible, if one remembers how tumor microenvironment may fluctuate during various stages of tumor development. Head and neck cancer cells encounter not only tumor-infiltrating lymphocytes, macrophages, proliferating endothelial cells and/or fibroblasts but also heavy burden of bacterial flora being constant phenomenon in advanced cancers. It certainly requires differentiated response to such rich panel of stimuli.
Co-culture of cells with ligands was aimed to show the effect of the latter on TLR expression. Unfortunately, not all TLRs ligands were available. Those which were, demonstrated rather unexpected pattern after $24 \mathrm{hrs}$ co-culture with tumor cells. Cytoplasmic TLR expression of cells was usually higher than that with ligand. TLR surface expression with ligand became however higher than without ligand, although this increase was not very impressive. It may suggest that cancer cell-ligand interaction may not necessarily lead to cell stimulation, as it is in the case of normal cells. Instead, it may result in transfer of TLR to cell interior, presumably to tumor advantage, as it has been shown recently for LPS -TLR4 interaction [22]. This is only the presumption that requires further study. An example of Drosophila indicates however, that TLRs may carry out other functions apart from the response to infection. Rydberg et al. [23] have demonstrated that head and neck squamous carcinoma cell lines, following culture with TLR agonists undergo inflammation or even cell death. We did not observe such phenomena, presumably due to relatively low dosage of ligand used as recommended by manufacturer. On the other hand, there are data from the literature that TLRs may prevent apoptosis, promote repair following lung injury, protect gut epithelium from injury etc [24]. There are also reports that some TLR agonists, such as imiquimod used in the 
current study, may have anti-tumor effect, both applied topically in skin cancers and as systemic one in melanoma [25].

In conclusion, the above presented data provide some evidence of almost universal expression of functional Toll-like receptors on laryngeal carcinoma cell lines. Their impact on tumor growth and progression remains to be elucidated.

Acknowledgements: Research described in this article was supported by the grant from the Polish Ministry of Science and Higher Education nr NN 401183333 (to J. Ż.).

\section{References}

[ 1] Chen R, Alvero AB, Silasi DA et al. Inflammation, cancer and chemoresistance: taking advantage of the toll-like receptor signaling pathway. Am J Reprod Immunol. 2007;57:93-107.

[2] Beutler BA. TLRs and innate immunity. Blood. 2009;113; 1399-1407.

[ 3] Chen K, Huang J, Gong W et al. Toll-like receptors in inflammation, infection and cancer. Int Immunopharmacol. 2007; 7:1271-1275.

[4] Balogh S, Kiss I, Csaszar A. Toll-like receptors: link between "danger" signals and plaque instability. Curr Drug Targets. 2009;6:513-518

[ 5] Knol AC, Ehst BD, Dompmartin A et al. Toll-like receptor 2, 4 and 9 expression in primary cutaneous CD30+ T-cell lymphoma. Br J Dermatol. 2009;161:1414-1426.

[ 6] Etokebe GE, Knezevic J, Petricevic B et al. Single-nucleotide polymorphisms in genes encoding toll-like receptor $-2,-3,-4$ in case - control study with breast cancer. Genet Test Mol Biomarkers. 2009;13:729-734.

[ 7] Droemann D, Albrecht D, Gerdes J et al. Human lung cancer cells express functionally active Toll-like receptor 9. Respir Res. 2005;6:1-10.

[ 8] Tang XY, Zhu YQ, Wei B, Wang H. Expression and functional research of TLR4 in human colon carcinoma. $\mathrm{Am} \mathrm{J} \mathrm{Med}$ Sci. 2010;339:319-326.

[9] Chang S, Kodys K, Szabo G. Impaired expression and function of Toll-like receptor 7 in hepatitis $\mathrm{C}$ virus infection In human hepatoma. Hepatology. 2010;51:35-42.

[10] Szajnik M, Szczepanski MJ, Czystowska M et al. TLR4 signaling induced by lipopolysaccharide or paclitaxel regulates tumor survival and chemoresistance in ovarian cancer. Oncogene. 2009;28:4353-4363.

[11] Żeromski J, Mozer-Lisewska I, Kaczmarek M. Significance of Toll-like receptors expression in tumor growth and spreading: a short review. Cancer Microenvironment. 2008;1:37-42.

[12] Tillman DK Jr, Caroll MT. Topical imiquimod therapy for basal and squamous cell carcinomas: a clinical experience. Cutis. 2007;79:241-248.

[13] Carneiro RC, de Macedo EM, Matayoshi S. Imiquimod 5\% cream for the treatment of periocular basal cell carcinoma. Ophtal Plas Reconstr Surg. 2010;26:100-102.
[14] Huang SJ, Hijnen D, Murphy GF et al. Imiquimod enhances IFN-gamma production and effector function of T cells infiltrating human squamous cell carcinomas of the skin. $J$ Invest Dermatol. 2009;129:2676-2685.

[15] Kundu SD, Lee C, Billips BK et al. The toll-like receptor pathway: a novel mechanism of infection-induced carcinogenesis of prostate epithelial cells. Prostate. 2008;68:223229.

[16] Chen R, Alvero AB, Silasi DA, Mor G. Inflammation, cancer and chemoresistance: taking advantage of the toll-like receptor signaling pathway. Am J Reprod Immunol. 2007;57:93107.

[17] Szczepański M, Stelmachowska M, Stryczyński Ł et al. Assessment of expression of toll-like receptors 2, 3 and 4 in laryngeal carcinoma. Eur Arch Otolaryngol. 2007;264:525530.

[18] Lin CJ, Grandis JR, Carey TE et al. Head and neck squamous carcinoma cell lines: established models and rationale for selection. Head \& Neck. 2007;29:163-188.

[19] Quon H, Liu FF, Cummings BJ. Potential molecular prognostic markers in head and neck squamous cell carcinomas. Head \& Neck. 2001;23:147-158.

[20] Verastegui E, Morales R, Barrera JL et al. Immunological approach in the evaluation of regional lymph nodes of patients with squamous carcinoma of the head and neck. Clin Immunol. 2002;102:37-47.

[21] Lemaitre B, Nicolas E, Michaut L et al. The dorsoventral regulatory gene cassette spatzle/Toll/cactus controls the potent antifungal response in Drosophila adults. Cell. 1996;86:973983.

[22] Kundu SD, Lee C, Billips BK et al. The toll-like receptor pathway: a novel mechanism of infection-induced carcinogenesis of prostate epithelial cells. Prostate. 2008;68:223229.

[23] Chen R, Alvero AB, Silasi DA, Mor G. Inflammation, cancer and chemoresistance: taking advantage of the toll-like receptor signaling pathway. Am J Reprod Immunol. 2007;57:93107.

[24] Szczepanski MJ, Czystowska M, Szajnik M et al. Triggering of Toll-like receptor 4 expressed on human head and neck squamous cell carcinoma promotes tumor development and protects the tumor from immune attack. Cancer Res. 2009;69:3105-3113.

[25] Rydberg C, Mansson A, Uddman R et al. Toll-like receptor agonists induce inflammation and cell death in a model of head and neck squamous cell carcinomas. Immunology. 2009;128(1 suppl):e600-611.

[26] O'Neill LAJ. TLRs play good cop, bad cop in the lung. Nature Medicine. 2005;11:1161-1162.

[27] Adams S, O'Neill DW, Nonaka D et al. Immunization of malignant melanoma patients with full length NY-ESO-1 protein using TLR7 agonist imiquimod as vaccine adjuvant. J Immunol. 2008;181:776-784.

Submitted: 9 November, 2009 Accepted after reviews: 16 May, 2010 